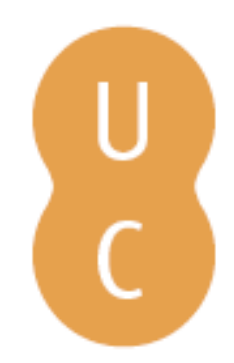

\title{
nommalina
}

\section{Comunidades sustentáveis como expressão social da sustentabilidade urbana}

\author{
Autor(es): $\quad$ Fumega, João
}

Publicado por: Imprensa da Universidade de Coimbra

URL

persistente: URI:http://hdl.handle.net/10316.2/30823

DOI: $\quad$ DOI:http://dx.doi.org/10.14195/978-989-26-0244-8_42

Accessed : $\quad$ 26-Apr-2023 04:51:53

A navegação consulta e descarregamento dos títulos inseridos nas Bibliotecas Digitais UC Digitalis, UC Pombalina e UC Impactum, pressupõem a aceitação plena e sem reservas dos Termos e Condições de Uso destas Bibliotecas Digitais, disponíveis em https://digitalis.uc.pt/pt-pt/termos.

Conforme exposto nos referidos Termos e Condições de Uso, o descarregamento de títulos de acesso restrito requer uma licença válida de autorização devendo o utilizador aceder ao(s) documento(s) a partir de um endereço de IP da instituição detentora da supramencionada licença.

Ao utilizador é apenas permitido o descarregamento para uso pessoal, pelo que o emprego do(s) título(s) descarregado(s) para outro fim, designadamente comercial, carece de autorização do respetivo autor ou editor da obra.

Na medida em que todas as obras da UC Digitalis se encontram protegidas pelo Código do Direito de Autor e Direitos Conexos e demais legislação aplicável, toda a cópia, parcial ou total, deste documento, nos casos em que é legalmente admitida, deverá conter ou fazer-se acompanhar por este aviso.

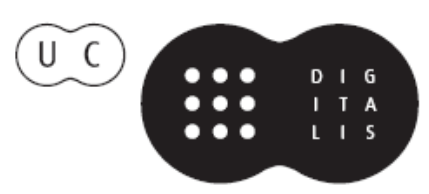




\section{TRUNFOS DE UMA}

\section{EOGRAFIA ACIVA}

\section{DESENVOLVIMENTO LOCAL,}

AMBIENTE,

ORDENAMENTO

E TECNOLOGIA

Norberto Santos

Lúcio Cunha

COORDENAÇÃO 
João Fumega

Centro de Estudos Geográficos, Instituto de Geografia e Ordenamento do Território (IGOT), Universidade de Lisboa

\section{COMUNIDADES SUSTENTÁVEIS COMO EXPRESSÃO SOCIAL DA \\ SUSTENTABILIDADE URBANA}

\section{INTRODUÇÃO}

A questão da sustentabilidade urbana tem vindo a ganhar crescente importância ao longo das últimas décadas. Existe no presente uma multiplicidade de abordagens a esta problemática, que têm diferido consoante os vários contextos a que se referem sejam eles geográficos, políticos, sociais, económicos ou de outro tipo. Este artigo, tem como base a dissertação desenvolvida pelo autor no âmbito do Mestrado em Gestão do Território e Urbanismo da Faculdade de Letras da Universidade de Lisboa, e tem como fim a análise de uma das vertentes da sustentabilidade que tem sido menos estudada, a social, através do conceito de comunidades sustentáveis, que visa colocar de novo no centro do desenvolvimento urbano a comunidade. Igualmente importante neste artigo será o conceito de capital social, pela importância que tem para uma comunidade, pois constitui o reflexo da forma como esta se organiza e estrutura os seus valores.

Este artigo estará estruturado em quatro capítulos: o primeiro capítulo referente à introdução, o segundo capítulo de explanação dos conceitos chave, terceiro capítulo sobre a metodologia e o caso de estudo, Campo de Ourique e por fim, o quarto capítulo, que diz respeito à análise de resultados e conclusôes.

\section{Comunidades Sustentáveis e a sua relaÇão COM O CONCEITO de Capital} SOCIAL

O conceito de sustentabilidade ganhou importância num contexto de insustentabilidade urbana e de um forte sentido de entendimento global do problema. Neste âmbito foi escolhido para análise o movimento das comunidades sustentáveis, pela importância que concede à componente social e comunitária da sustentabilidade que muitas vezes é relegada para segundo plano como elemento essencial para uma cidade. Algumas definiçóes são apontadas para este conceito, sendo que é bastante importante a definida por Egan (2004:18) no relatório "Skills for sustainable communities":

"Sustainable communities meet the diverse needs of existing and future residents, their children and other users, contribute to a high quality of life and provide opportunity and 
choice. They achieve this in ways that make effective use of natural resources, enhance the environment, promote social cohesion and inclusion and strengthen economic prosperity."

É crucial para o entendimento do conceito de comunidade sustentável, o conceito de capital comunitário. Assim, capital comunitário em termos de desenvolvimento sustentável pode ser visto como um bem ou capital, que é criado despendendo tempo e esforço em actividades de transformação ou transacção (Ostrom in Roseland, 2004:4). Na perspectiva das comunidades sustentáveis, o capital comunitário divide-se em capital natural, físico, económico, humano, social e cultural.

Egan (2004), identificou sete componentes que caracterizam e aplicam o conceito de Comunidades Sustentáveis. Elas estão todas inter-relacionadas, e têm como objectivo focar cada elemento constituinte de uma comunidade sendo elas: governância, transportes e conectividade, serviços, ambiente, economia, habitação e ambiente construído e sociedade e cultura, sendo que para cada componente é definido um princípio que a caracteriza. A 'Homes and Communities Academy', (GAASC, 2009), acrescenta a equidade às componentes de Egan, desenvolvendo também os atributos de cada uma delas.

Por motivos de exequibilidade, foram analisadas apenas três componentes, que de acordo com as características do caso de estudo, foram entendidas como as mais relevantes na aplicação do conceito de comunidades sustentáveis, sendo que à componente dos serviços foram acrescentados os equipamentos: componente sociocultural, serviços e equipamentos e transportes e conectividade. A componente sociocultural, de acordo com Egan (GAASC, 2009) tem como atributos ser activa, inclusiva e segura. Tem como objectivo ser justa, tolerante e coesa com uma cultura local forte e outras actividades comunitárias partilhadas. Esta componente deve oferecer um sentido de identidade e pertença à comunidade; respeito por pessoas de diferentes culturas e credos; cooperação e espírito de abertura com os bairros vizinhos; oportunidades para o lazer, cultura, desporto e outras actividades que sejam acessíveis para idosos e crianças; baixos níveis de crime, drogas e comportamento anti-social apoiados por 'vigilância' comunitária e inclusão social.

A componente dos serviços e equipamentos, de acordo com Egan (GAASC, 2009), diz respeito a uma comunidade bem servida, com serviços de carácter público, privado, comunitário e voluntário que são apropriados às necessidades das pessoas e acessíveis a toda a populaçáo. Uma comunidade sustentável, na óptica desta componente, deverá ter escolas locais, instituiçôes de ensino superior e outras oportunidades de ensino para idosos de alta qualidade; serviços de saúde e sociais de elevada performance associados com outros serviços; serviços de apoio às famílias e às crianças; um bom leque de serviços acessíveis a toda a comunidade monetariamente, como por exemplo, comida fresca, comércio, utilidades, informação, etc.; prestadores de serviços que actuem a longo prazo e além das suas barreiras geográficas e de interesse mais próximas, em concertação com a população.

O objectivo da componente dos transportes e conectividade, segundo Egan (GAASC, 2009) é assegurar a boa ligação dos bairros entre si e entre as estruturas urbanas inferiores (corredor, rua) e superiores a estes (cidade, regiáo). Para isso têm que existir bons serviços de transportes e comunicação, ligando pessoas, empregos, escolas, equipamentos de saúde e outros serviços. Na lógica das comunidades sustentáveis devem existir infra-estruturas de transporte adequadas, incluindo transporte público que ajude as pessoas a viajar na, e entre comunidades, reduzindo a dependência do automóvel; condiçôes para a promoção da deslocação a pé e do uso da bicicleta; nível apropriado de oferta de estacionamento assim como planos adequados de 
gestão de tráfego; serviço constante e de qualidade de telecomunicaçóes e acesso à internet; e bom acesso às redes de comunicaçáo regionais, nacionais e internacionais.

Imprescindível, para o desenvolvimento do conceito de comunidades sustentáveis é a promoçâo do capital social. A potencialização deste conceito é indissociável dos processos participatórios, onde é possível encontrar equidade no desenvolvimento e melhor aplicar o conceito de sustentabilidade sem grandes fracturas com o território. Em geral, estratégias na óptica do desenvolvimento sustentável, como são o caso das comunidades sustentáveis, devem favorecer a abordagem bottom-up em relação à abordagem top-down, redistribuição, autosuficiência, focus local, projectos de pequena escala, assim como incluir uma participaçáo pública extensa, melhorar a sociedade e o ambiente assim como a economia, que resulta em equidade, igualdade e empowerment (Brohman, 1996 in Roseland, 2007:26).

O pilar central da comunidade é a sua participação, mobilização no processo de construção do seu bairro e identidade. Quanto mais participação existir, e quanto mais se investir na qualidade desta e na transmissão de certas responsabilidades para as pessoas, melhor uma comunidade poderá progredir. Assim, através do reforço das dimensóes do capital social, nomeadamente das redes sociais, civismo e confiança, é possível potencializar a comunidade de determinado local, tornando-a mais activa e interveniente na vida do seu bairro. Contudo, tal só é possível também se existirem as condiçóes adequadas no bairro, nomeadamente se este for bem servido no que respeita às várias componentes das comunidades sustentáveis. A existência de escolas, locais de encontro, oportunidade de deslocaçáo a pé que propiciem o encontro fortuito, comércio de bairro, entre outros, irão contribuir positivamente para a afirmação e potencialização das dimensóes atrás descritas do capital social. A deterioração de um conceito irá enfraquecer o outro, criando-se assim um ciclo relacional de importância vital, no fundo, de um lado o ambiente construído, o suporte físico vital para o bem-estar e desenvolvimento harmonioso de uma comunidade, e do outro a estrutura social que dá identidade ao bairro e que suporta a sua existência como comunidade.

\section{MeTOdOLOGIA E CASO DE ESTUdO}

A área de análise situa-se na freguesia de Santo Condestável, que, a par da freguesia de Santa Isabel, constituem as duas freguesias do bairro de Campo de Ourique. A escolha desta área prendeu-se com o seu desenho urbano e diversidade funcional, que vai muito de encontro ao que são as características do conceito de unidade de vizinhança, mas também vai de encontro a várias características que são definidas aquando do conceito de comunidades sustentáveis, assim como pela expressão que as relaçóes sociais têm neste bairro. Esta compreende o mercado de Campo de Ourique, a Igreja de Sto. Condestável, o antigo Cinema Europa, a Junta de Freguesia, o Jardim da Teófilo Braga, além de uma forte diversidade de serviços, comércio e presença de transporte público.

A análise estatística centrou-se na informação disponível nos censos de 1981, 1991 e 2001 para as freguesias que compóem o bairro de Campo de Ourique, com vista a assim melhor entender a evolução da população residente, as famílias e os edifícios ao longo dos anos, bem como dar resposta a indicadores que foram definidos por Egan (2004) para cada componente a analisar. Foram também analisados os indicadores "Fogos licenciados (N.o) em construçóes novas para habitação familiar por Localização geográfica e Entidade promotora" e "Fogos licenciados (N.o) em construçóes novas para habitação familiar por 
Localização geográfica e Tipologia do fogo" desde 1995-1998. Pretendeu-se com esta análise perceber como estes indicadores podem influenciar a capacidade atractiva do bairro. Foi também analisado um estudo bastante importante para a compreensão das dinâmicas do bairro de Campo de Ourique, intitulado "Diagnóstico Sócio-urbanístico da Cidade de Lisboa - Uma perspectiva censitária” (2001).

A análise do Bairro foi complementada com a realização de inquéritos à população, inquéritos que foram realizados na freguesia de Santo Condestável, onde se situa a área de análise, sendo que consideraram-se 3 áreas, com diferentes níveis de dotação de comércio, serviços e equipamentos. A amostra consistiu em 100 pessoas e respectivos agregados sendo que 26 destas, são não moradoras e 74 são moradoras na área de análise.

$\mathrm{O}$ inquérito estava estruturado em três pontos: caracterização geral, à qual corresponde a caracterização do indivíduo e do respectivo agregado familiar, incluiu também uma secção de perguntas destinadas aos não moradores; dimensão comunidades sustentáveis, que é composta pelas três componentes atrás ilustradas; e finalmente uma terceira dimensão, que é a do capital social dividida nas componentes redes sociais, confiança e civismo. No caso das comunidades sustentáveis as perguntas tiveram como fonte o relatório Egan (2004), assim como a Tese de Doutoramento do Professor Nuno Marques da Costa, da Faculdade de Letras da Universidade de Lisboa. No caso do capital social, as perguntas tiveram como fonte o estudo "European Values Study", nomeadamente o inquérito-modelo que foi aplicado em 2008. Fundamental na escolha das dimensóes de capital social a serem analisadas foi também o trabalho de van Oorschot et al (2006:153), no qual foram delineadas as dimensôes do capital social mais indicadas para a sua medição e respectivos indicadores.

Foi feita cartografia para três tipos de análise: levantamento funcional, com vista aferir a multiplicidade de funçóes e serviços que existem; levantamento da época de construção, com o objectivo de identificar espacialmente a distribuição do edificado por idade; e levantamento do estado de conservação do edificado, para perceber as características do edificado a este nível no bairro.

A informação recolhida foi complementada com a realização de entrevistas, que tiveram como objectivo perceber as políticas que estão a ser desenvolvidas na área de estudo, como estas são pensadas ao nível do poder local, como a Câmara de Lisboa, e ao nível regional, como é o caso da CCDR-LVT. Por fim, mas não menos importante, foram utilizadas para ter uma ideia do pensamento científico que está a ser desenvolvido no presente sobre esta temática, como é exemplo a entrevista realizada ao Professor John Fernandez, do MIT.

\section{ANÁLISE DE RESULTADOS E CONCLUSÓES}

A análise do caso de estudo evidenciou um conjunto de aspectos característicos das áreas centrais das cidades, mas permitiu também identificar um conjunto de sinais e de níveis relacionais, que, potenciados, podem constituir orientaçóes chave para a constituição de comunidades sustentáveis.

Assim, Campo de Ourique tem revelado uma constante quebra de população, sendo que cada vez mais as suas famílias são menos numerosas. Uma parte importante da populaçáo (cerca de 55\%) ainda tem um grau de escolaridade inferior ao secundário, registando-se também um aumento da presença de população reformada. A maioria da população activa, 
possui profissóes no grupo dos técnicos de nível intermédio, sendo que $37 \%$ trabalha em Campo de Ourique. No que respeita ao edificado, este é na sua maioria da $1^{\text {a }}$ metade do século XX, sendo que se encontra num estado razoável/bom. A influência do comércio no bairro faz-se sentir no número crescente de edifícios com outra ocupaçáo que não a residencial.

A análise dos inquéritos permitiu aprofundar estes dados e entender de uma forma mais completa a problemática/atractividade de Campo de Ourique. Os inquéritos realizados aos não moradores mostram uma população activa mais jovem, com maior grau de instruçáo, ligada ao sector dos serviços, sendo que a maioria vem de fora de Lisboa e deslocam-se ao bairro para efectuar compras ou usufruir de serviços.

Fazendo uma comparação dos resultados dos inquéritos com a caracterização funcional do bairro, pode-se denotar que existe uma correlação forte entre a existência de um equipamento ou actividade e o seu uso e a satisfação relativamente a estes. Mais, a estrutura ortogonal e plana do bairro, é em si mesma potenciadora de uma maior variedade e vitalidade das actividades existentes, pois é fácil de assimilar por parte de não moradores, possui uma melhor mobilidade para moradores e não moradores, e possui várias esquinas e pontos de contacto que são essenciais para uma maior visibilidade das actividades existentes e possibilita maiores oportunidades de encontro fortuito. Note-se o comércio, por exemplo, que obtém elevados índices de satisfação, que são explicados através da carta de levantamento funcional onde se pode observar uma variedade considerável de comércio. $\mathrm{O}$ mesmo se pode dizer no sentido inverso, nomeadamente a falta de práticas desportivas e culturais e também insatisfação, que estão muito associadas à falta destes equipamentos. Note-se, por exemplo, que na dimensão das redes sociais cerca de $72 \%$ das pessoas inquiridas nunca fez nenhum trabalho voluntário nem pertenceu a uma associação, o que pode estar relacionado com a presença diminuta de equipamentos colectivos, onde as pessoas se encontrem todos os dias, criem laços e construam uma cultura de entreajuda e associativismo. Neste sentido pode-se afirmar que a existência de equipamentos e diversidade de actividades é essencial para o bem-estar de uma comunidade, contribuindo para a sua sustentabilidade, caso estes não tenham qualidade ou simplesmente não existam, a população tende a usá-los menos, deteriorando a sua qualidade de vida.

Contudo, igualmente importante é o bem-estar relativo às questóes da identificação, apropriação do território, criação de laços, e neste aspecto encontra-se uma importante ligaçáo entre as componentes das comunidades sustentáveis e as dimensóes do capital social. Assim, uma percentagem elevada de pessoas afirma-se 'muito feliz' (56\%) e ainda mais elevada afirma-se 'muito feliz' com o bairro de Campo de Ourique (73\%). Como já foi enunciado, alguma desta percentagem pode ser explicada pela presença de infra-estruturas adequadas, contudo, de elevada importância para este valor sáo certamente indicadores resultantes de dimensóes de capital social como a confiança, na qual cerca de $82 \%$ das pessoas afirmaram que as pessoas de Campo de Ourique são de confiança, ou das redes sociais, na qual a maioria parte das pessoas afirma que está todos os dias com família e amigos.

Finalmente, importantes também foram os resultados relativos aos moradores mais recentes, pois constituem um grupo de pessoas que conhecem o território de uma forma menos profunda, induzem nele novas características, contribuindo de certa forma para perceber tendências futuras de transformação do espaço. Assim, apesar de uma predominância de 50\% de moradores que vivem há mais de 30 anos no bairro, o segundo valor mais expressivo diz respeito aos moradores que vivem no bairro há 10 ou menos anos, e que corresponde quase a $30 \%$, o que indica uma capacidade de atractividade bastante interessante deste bairro. Mais, os 
novos moradores possuem, na sua maioria (45\%) grau de ensino superior, o que indica que é população qualificada aquela que tem vindo morar para Campo de Ourique. Quando inquirida a população que se mudou para Campo de Ourique acerca das razóes por detrás desta escolha o principal factor é a 'família/amigos' (23\%), o que comprova a forte coesão social que existe no bairro e os fortes laços familiares, 'habitaçáo' (18\%) explicada pelas cartas de idade e estado de conservaçáo do edificado, nas quais se conclui que o edificado está num estado razoável de conservaçáo, 'trabalho' (14\%) explicado pelas forte diversidade de actividades e 'gosta do local' (12\%) que pode agrupar um pouco de todas as respostas anteriores mas que inclui também questóes culturais e sociais específicas do bairro de Campo de Ourique. Assim, encontram-se sumariamente definidas as principais valências deste bairro: coesão social, habitação de uma forma geral em bom estado de conservação, diversidade de actividades, e um local com uma identidade cultural e social com relevância, todos eles aspectos com uma forte correlação com o conceito de comunidades sustentáveis.

Estes aspectos consubstanciam algumas conclusóes, que devem constituir elementos de referência para a sugestão de recomendaçóes que permitam reforçar o Bairro de Campo de Ourique como uma comunidade sustentável, ou de uma forma geral, que constituam orientaçóes genéricas para outros bairros:

- a existência de uma população mais envelhecida com fortes ligaçóes ao bairro, coexiste com a capacidade de atracção de novos residentes, sendo este mix social e geracional um dos pontos a salientar na dinâmica do bairro e que é indiciador da importância do capital social e relacional para a sustentabilidade urbana;

- a forma urbana das áreas centrais e consolidadas das cidades, coadjuvadas pela recuperação do comércio, serviços, equipamentos, infra-estruturas e edificado, podem contribuir para a revitalizaçáo das zonas centrais, quer do ponto de vista demográfico, quer do ponto de vista social e, assim, constituírem elementos chave para a definição de comunidades sustentáveis;

- a importância do estabelecimento ou potenciação de comunidades sustentáveis à escala do bairro, para a reabilitação das áreas centrais e envelhecidas das cidades, contribuindo para um modelo de desenvolvimento urbano mais sustentável.

Os desafios que se colocam ao conceito de comunidades sustentáveis estão em parte relacionados com a sua abordagem integradora, que tem como vista o longo prazo, a sustentabilidade das acçóes que são aplicadas em determinado território. Portanto, o de tentar conciliar visóes e ferramentas díspares mas que intervêm no mesmo território, e também o de tornar uma série de princípios teóricos numa série de práticas e ensinamentos. No caso do primeiro desafio a soluçáo passa pelo conceito de governância, portanto, fomentar a parceria entre os vários agentes, organismos, departamentos que intervém no território e uma melhor organização e estruturação das responsabilidades, objectivos e modos de funcionamento de cada organismo. Relativamente ao segundo desafio, é interessante reflectir qual a direcção a tomar: será que deve existir uma série de guidelines que devem ser aplicadas a qualquer realidade? Ou por outro lado deve existir uma maleabilidade que se irá adaptar às diferentes especificidades do território? Segundo a literatura consultada e as entrevistas realizadas, a segunda possibilidade é a mais evidente. Contudo, torna-se essencial clarificar, sobretudo para a população, os objectivos do conceito de comunidades sustentáveis, as características que o distinguem dos restantes conceitos, e sobretudo, como se pode operacionalizar o conceito. A solução para esta questão passa por uma maior capacidade associativa, uma maior 
coesão por parte da comunidade científica que estuda e desenvolve este conceito, um pouco à semelhança do que foi feito com a Carta do Novo Urbanismo, e melhor divulgação de casos de estudo de exemplos de aplicaçáo do conceito. A comunidade é a forma elementar de organização de um grupo de pessoas que partilha um espaço, uma cultura e respectivos valores societais. Sendo esta a forma básica de organização humana, torna-se lógica a construção a partir deste ponto da sustentabilidade urbana. Só tendo em atenção as necessidades das pessoas, as suas características como um grupo e respectivas potencialidades, se poderá promover uma melhor qualidade de vida de acordo com as necessidades de uma população, e de uma comunidade, que se organiza sucessivamente em várias escalas desde o bairro até à escala planetária.

\section{REFERÊNCIAS BIBLIOGRÁFICAS}

Câmara Municipal de Lisboa 2004, Diagnóstico Sócio-urbanistico da Cidade de Lisboa - Uma perspectiva censitária, Pelouro de Licenciamento Urbanístico e reabilitação Urbana, Coordenação de João Seixas, C.M.L, 2001.

Costa, Nuno Marques da 2008, Mobilidade e transporte em áreas urbanas: o caso da área metropolitana de Lisboa, Tese de doutoramento em Geografia (Geografia Humana), apresentada à Universidade de Lisboa, Faculdade de Letras.

Egan, J. 2004, The Egan Review: Skills for sustainable communities, Office of the Deputy Prime Minister, Ed. Crown Copyright, London.

European Values Study 2008, Final questionnaire for European value survey - Master Questionnaire, Ed. European Values Study.

Farr, D. 2008, Sustainable Urbanism: Urban Design With Nature, Ed. John Wiley \& Sons, Inc., Hoboken, New Jersey.

Geographical Association and Academy for Sustainable Communities 2009, Componentes das Comunidades Sustentáveis, disponível em: www.geography.org.uk/projects/buildingsustainablecommunities

Health Canada 2003, Social capital as a health determinant: how is it defined, Health Policy Research Working Paper Series, Canada.

INE 1981-2001, XII, XIII, XIV Recenseamentos Gerais da População, Censos 1981-2001.

INE anual, Inquérito aos Projectos de Obras de Edificação e de Demolição de Edifícios: Fogos licenciados (N. ${ }^{\circ}$ em construçôes novas para habitação familiar por Localização geográfica e Entidade promotora, ed. INE

Putnam, R. D. 2000, Bowling Alone: The collapse and revival of American community, Ed. Simon \& Schuster paperbacks, New York.

Roseland, M. 2005, Toward Sustainable Communities: revised edition, Ed. New Society Publishers, Canada.

Van Oorschot et al 2006, "Social capital in Europe: measurement and social and regional distribution of a multifaceted phenomenon", Acta Sociologica, vol. 49, pp.149. 